\title{
Longitudinal evaluation of manual lymphatic drainage for the treatment of gynoid lipodystrophy*
}

\author{
Bianca Schonvvetter ${ }^{1}$ \\ Ediléia Bagatin ${ }^{1}$
}

Juliana Laudicéia Marques Soares ${ }^{1}$

DOI: http://dx.doi.org/10.1590/abd1806-4841.20143130

\begin{abstract}
BACKGROUND: The gynoidlypodystrophy, known as cellulitis or cellulite, refers to a condition that gives the skin an undulating and uneven appearance, affecting 80-90\% of women after puberty.

OBJECTIVES: to investigate the efficacy and safety of manual lymphatic drainage for cellulite management.

METHODS: this was an open, prospective, intervention study including 20 women aged from 20 to 40 years. Fourteen sessions of manual lymphatic drainage were performed once a week on lower limbs and buttocks.

RESULTS: Fifteen women completed the study. A significant improvement on quality of life was observed $(p=0.018)$. A significant reduction ( $p=0.023$ ), estimated at $0.3 \pm 0.8 \mathrm{~cm}$, in hip circumference was found, but no difference was found in thighs circumference $(p>0.05)$. A significant reduction elastic recuperation of skin on buttocks, which means skin elasticity worsening, was observed. All measures obtained by ultrasound images showed no changes $(p>0.05)$. CONCLUSION: manual lymphatic drainage was safe but not effective as an isolated approach for cellulite management. Further randomized, controlled or comparative studies about manual lymphatic drainage for cellulite control, as unique or combined therapeutic modality, are necessary.
\end{abstract}

Keywords: Cellulitis; Drainage; Massage

\section{INTRODUCTION}

The term cellulite refers to a condition that gives the skin an uneven, dimpled, orange peel-like appearance and is observed mainly on women's thighs and buttocks after puberty. ${ }^{1}$ So far, this apparently multifactorial disorder is believed to be caused by the following factors: anatomical changes; microcirculation failure; reduced production of the vasodilator hormone adiponectin by the subcutaneous cell tissue; genetic polymorphism; changes in dermal connective tissue; and inflammatory processes. ${ }^{2-4}$ The method most widely used to classify cellulite is that proposed by Nürnberger and Müller, which was based on 4 grades defined according to clinical presentation: zero: no changes; I: visible changes at skin clamping or muscle contraction; II: visible changes when there is no manipulation; and III: visible changes associated with nodulations (Figures 1 e 2 ). ${ }^{1}$

The methods used to evaluate the severity of cellulite include: anthropometric measurements, macro photography, bioelectrical impedance, thermogram, Doppler flowmetry, high-resolution twodimensional ultrasound (US), nuclear magnetic resonance imaging, and skin biopsy followed by histologi- cal examination. ${ }^{2,5-7}$ Given the esthetic repercussion of this condition and the fact that its etiopathogeny has been partly understood already, many treatments have been proposed, such as: balanced diet regular physical activity; massage; topical products with vegetable ingredients, such as caffeine, and topical retinoids; endermologie; radiofrequency (RF); focused US; laser; infrared light emitting diode (LED); and extracorporeal pulse activation therapy (EPAT), also known as acoustic wave therapy (AWT). ${ }^{5,8-17}$ However, none of these treatments provides fully satisfactory and lasting results that could be proved in studies with good methodology. ${ }^{10}$ The technique of manual lymphatic drainage (MLD), developed by the Danish biologists Emil and Estrid Vodder in 1936, is one of the main pillars of the treatment of lymphedema, because its movements help lymphatic circulation. ${ }^{18}$ Its purpose is draining fluids accumulated between interstitial spaces, particularly in dermis, collaborating thus for tissue fluid balance by means of pressure differentials that will promote the displacement of lymph and interstitial fluid towards the bloodstream. Superficial and gentle maneuvers are performed throughout the

Received on 10.09.2013

Approved by the Advisory Board and accepted for publication on 11.12.2013.

* Work conducted at the Cosmetology Unit, Department of Dermatology, Escola Paulista de Medicina, Universidade Federal de São Paulo (EPM-UNIFESP) São Paulo (SP), Brazil.

Financial Support: Fundação de Amparo à Pesquisa do Estado de São Paulo (FAPESP) - Process No. 2011/51633-8.

Conflict of Interest: None.

Universidade Federal de São Paulo (UNIFESP) - São Paulo (SP), Brazil.

(C)2014 by Anais Brasileiros de Dermatologia 


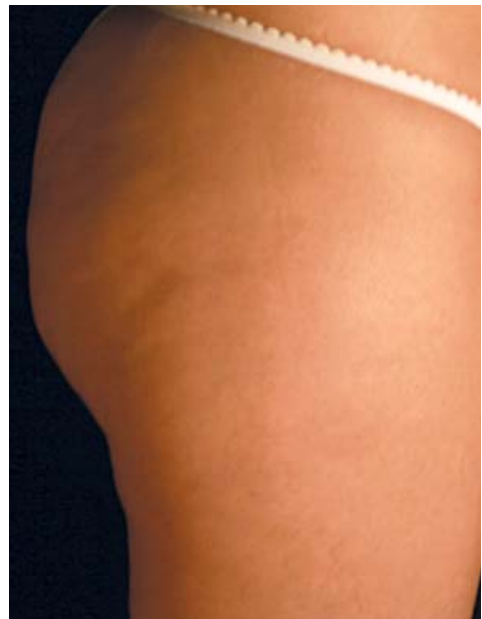

Figure 1:

Cellulite grade II

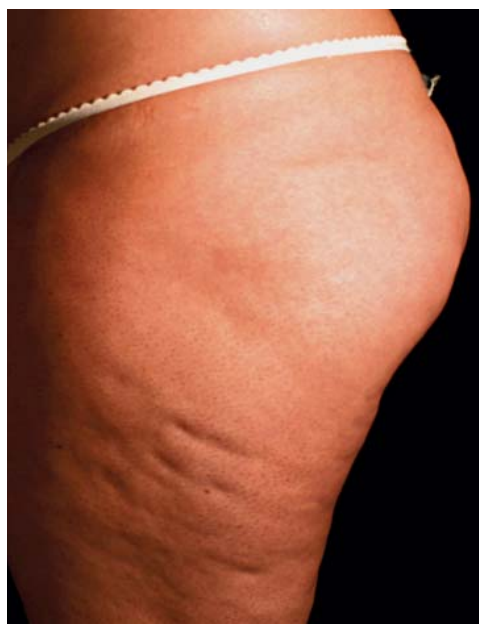

Figure 2:

Cellulite grade III

path of lymphatic vessels to eliminate lymph fluids and reduce edema. ${ }^{19}$

Considering that MLD is a technique aimed at stimulating the lymphatic system, reducing fluid excess, and eliminating metabolic waste, and that cellulite seems to be related to metabolic changes and fluid accumulation in dermal connective tissue leading to the worsening of anatomical characteristics, MLD may be beneficial in the control of this condition. ${ }^{9}$ This study aimed to investigate the efficacy and safety of MLD in improving the appearance of the skin with cellulite and the influence of this technique on quality of life.

\section{METHODS}

This is an open, prospective, intervention study including 20 women with cellulite on the upper third of thigh and buttocks who came from the general cosmetology outpatient clinic of an academic institution. Before participating in the study, all of them signed an informed consent form (ICF). Inclusion criteria were healthy women aged from 20 to 40 years who presen- ted with cellulite grade II or III on the buttocks, according to the classification by Nürnberger and Müller. 1

After clinical evaluation, MLD sessions were carried out once a week for 14 weeks. In these sessions, movements of physical stimulation and massage on lower limbs and buttocks were performed according to the techniques proposed by Vodder and Leduc. ${ }^{19}$

Parameters of efficacy were the following: subjective assessment (patient's and investigator's opinion regarding improvement in clinical signs of cellulite as measured by a 3-point scale: 1 = worsening; 2 = no change; 3 = improvement); blind evaluation by three independent physical therapists about whether there was a change in cellulite grade after treatment, using digitally captured photographs (OMNI,USA); weight; height; Body Mass Index (BMI) $\left(\mathrm{Kg} / \mathrm{m}^{2}\right)$; bioelectrical impedance (BIA 101 Quantum, RJL Systems, Detroit, MI, USA); measure of skin elasticity or cutometry (Cutometer MPA580тм, Courage \& Khazaka, Cologne, Germany); high-resolution US (DermaScan-Стм, Cortex Technology, Denmark) for measuring dermal thickness and echogenicity and the interface line between dermis and hypodermis (this skin layer was not evaluated due to method limitations); and application of a generic questionnaire on quality of life in dermatology named Dermatology Life Quality Index (DLQI).

Statistical analysis was performed using Mann Whitney, Fisher's exact and likelihood ratio tests (since the chi-square test did not show to be adequate because it is an asymptotic test), as well as box-plot charts and the Wilcoxon test. The agreement between patients' and examiners' opinion and between examiners' opinion between each other were evaluated using the kappa coefficient and its respective confidence interval, with a confidence level of $95 \%$ $(95 \% \mathrm{CI})$. This agreement was analyzed using the classification proposed by Landis and Koch. ${ }^{20}$

Data on biometry, physical examination, dermatoscopy, and cutometry obtained before and after MLD sessions were described as mean \pm standard deviation and compared by the paired $t$-test. The level of significance was set at $5 \%$, i.e., results were considered statistically significant if the $p$-value was below $5 \%(p<0.05)$.

\section{RESULTS}

Fifteen women aged between 22 and 38 years, with a mean age of 30 years and a standard deviation of 4 years, completed the treatment. Five women dropped out from the study because they had difficulty in attending the weekly massage sessions, and other two women dropped it out because they expected faster results.

Analysis was performed per protocol, because the cases that were excluded earlier underwent few 
massage sessions (from 1 to 3 sessions), which would not provide any improvement, a fact that occurred even in patients who finished the treatment.

All the variables assessed before the beginning of MLD sessions were compared between women who completed the study (Study Group) and those who were excluded earlier (Dropout Group) to investigate whether some variable might differ between the two groups.

It was observed that women who dropped out from the study earlier did not differ from those who completed it in terms of age, use of contraceptives, alcohol use, and practice of physical activity $(p>0.05)$. However, there was a higher percentage of women who controlled the diet among those who dropped out from the study $(60 \%)$ compared to those who completed it $(7 \%)$, with a significant difference $(p=0.032)$.

With regard to the 15 women who completed the study, sociodemographic data were the following: mean age of 29 years old, with a standard deviation of nearly four years, ranging from 22 to 33 years of age. A total of $53.3 \%(8 / 15)$ women used contraceptives; $47 \%(7 / 15)$ performed physical activities; as per alcohol use, the most frequent answer was "sometimes", reported by $73.3 \%(11 / 15)$ of women, followed by "never", reported by $20 \%$ (3/15), and "often", reported by only $6.7 \%$ (1/15). Most participants, i.e., $93.3 \%$ $(14 / 15)$ did not control their diet.

Figure 3 show that median, first and third quartiles for DLQI scores were 4,3 and 5 points before treatment and changed to 3,0 and 5 points, respective$1 y$, at the end of the treatment. Therefore, median DLQI scores at the beginning of the study were significantly higher than those from the end of the study, i.e., the treatment provided significant improvement in quality of life $(p=0.018$, Wilcoxon test) in terms of the psychological domain.

According to table 1, it can be observed that none of the patients reported worsening of cellulite, while $53 \%(8 / 15)$ reported improvement. However, according to examiners' opinion, there were worsening in two patients, and the most frequent result was "no change", accounting for $53.3 \%(8 / 15)$ and $60 \%(9 / 15)$ of evaluations from examiners 1 and 2, respectively.

Table 2 shows the joint distribution of opinions of examiners 1 and 2 to investigate the degree of agreement. Kappa value was k=0.173 (95\% CI [0-0.621]), i.e., there was low agreement between examiners.
Before treatment, $93.3 \%(14 / 15)$ of women had grade II cellulite on the buttocks, meaning that changes on skin surface were visible to the naked eye; of these, $60 \%(9 / 15)$ had the same grade after treatment and $33.3 \%(5 / 15)$ changed their grade to grade I cellulite, showing visible changes on skin surface under skin clamping. Figures 4 and 5 present a case of cellulite that did not experience any change in grade after treatment.

Table 3 evidences that treatment with MLD did not provide any difference in biometric measures for the thigh $(p>0.05)$. However, a significant reduction was found for hip measures $(p=0.023)$, which was estimated at $0.3 \pm 0.8 \mathrm{~cm}$.

Body mass index (BMI) and body fat percentage $(\mathrm{BF} \%)$ did not had a significant reduction $(\mathrm{p}>0.05)$ when comparing pre- and post-treatment values (Table 4).

There was a significant reduction in the parameter R7 $(p<0.05)$, indicating that there was a worsening of skin elasticity, as shown in table 5 . Mean estimated reduction in R7 was $0.102 \pm 0.013$ on the right side and $0.147 \pm 0.042$ on the left side.

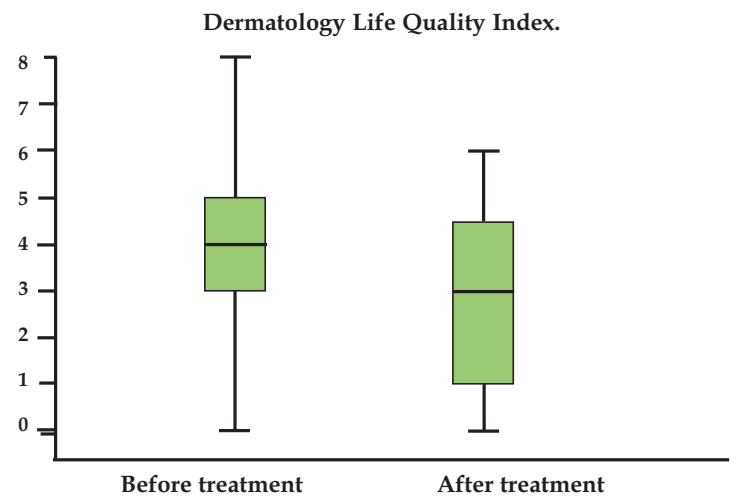

FIGURE 3: Boxplot of DLQI scores before and after treatmentt

TABLE 1: Frequency distribution of patients' and examiners' opinion regarding the improvement of cellulite

\begin{tabular}{llll}
\hline & \multicolumn{3}{c}{ Opinion } \\
\cline { 2 - 4 } Worsening & Patients & Examiner 1 & Examiner 2 \\
No change & $7(46.7 \%)$ & $1(6.7 \%)$ & $2(13.3 \%)$ \\
Improvement & $8(53.3 \%)$ & $6(40.0 \%)$ & $9(60.0 \%)$ \\
Total & $\mathbf{1 5 ( 1 0 0 . 0 \% )}$ & $\mathbf{1 5 ( 1 0 0 . 0} \%)$ & $\mathbf{1 5 ( 1 0 0 . 0 \% )}$ \\
\hline
\end{tabular}

TABLE 2: Simultaneous distribution of frequencies of opinions from examiners 1 and 2 regarding the improvement of cellulite

\begin{tabular}{lllll}
\hline Opinion Examiner 1 & \multicolumn{3}{c}{ Opinion Examiner 2 } & \multirow{2}{*}{ Total } \\
\cline { 2 - 4 } & Worsening & No change & Improvement & \\
\hline Worsening & $1(6.7 \%)$ & - & - & $1(6.7 \%)$ \\
No change & $1(6.7 \%)$ & $5(33.3 \%)$ & $2(13.3 \%)$ & $8(53.3 \%)$ \\
Improvement & - & $4(26.7 \%)$ & $2(13.3 \%)$ & $6(40.0 \%)$ \\
\hline Total & $\mathbf{2 ( 1 3 . 4 \% )}$ & $\mathbf{9 ( 6 0 . 0 \% )}$ & $\mathbf{4 ( 2 6 . 6 \% )}$ & $\mathbf{1 5 ( 1 0 0 . 0 \% )}$ \\
\hline
\end{tabular}



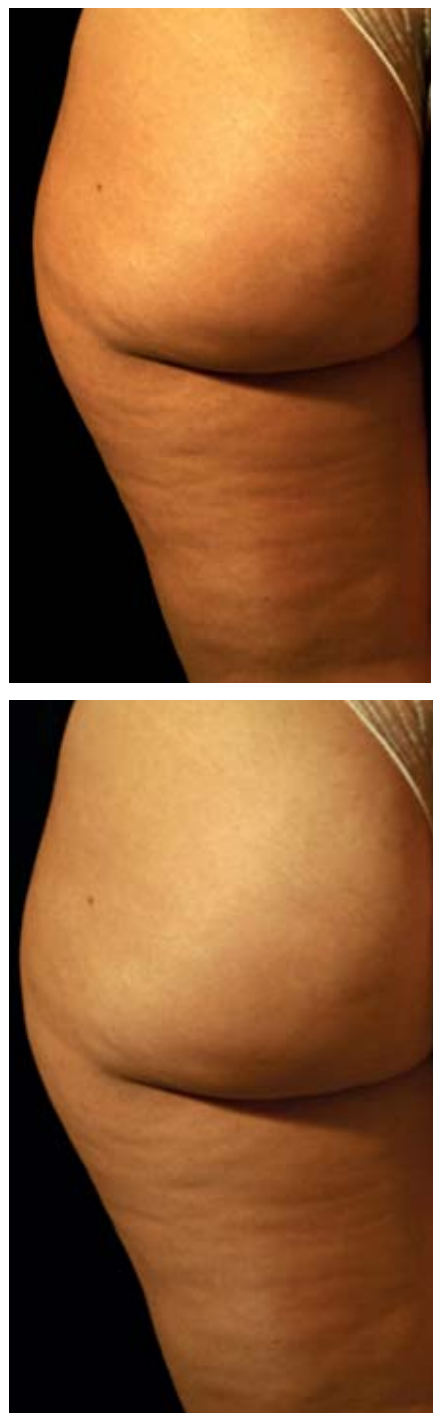

Figure 5:

Post-treatment photograph showing no change in the grade of cellulite

TABLE 3: Comparison between pre- and post-treatment biometric measures

\begin{tabular}{lccc}
\hline & $\begin{array}{c}\text { Before } \\
\text { treatment }\end{array}$ & $\begin{array}{c}\text { After } \\
\text { treatment }\end{array}$ & p-value \\
\cline { 2 - 4 } $\begin{array}{l}\text { Hip biometric } \\
\text { measures }(\mathrm{cm})\end{array}$ & $106.0 \pm 12.0$ & $105.7 \pm 12.4$ & 0.023 \\
$\begin{array}{l}\text { Right thigh biometric } \\
\text { measures }(\mathrm{cm})\end{array}$ & $59.2 \pm 8.7$ & $59.7 \pm 8.0$ & 0.527 \\
$\begin{array}{l}\text { Left thigh biometric } \\
\text { measures }^{\text {a }}(\mathrm{cm})\end{array}$ & $58.2 \pm 8.5$ & $58.9 \pm 8.8$ & 0.310 \\
\hline $\begin{array}{l}\text { a. for data on thighs } \mathrm{n}=11 \\
\text { \# paired t-test }\end{array}$
\end{tabular}

TABLE 4: Comparison between pre- and post-treatment measures for body mass index (BMI) and body fat percentage $(\mathrm{BF} \%)$

\begin{tabular}{llll}
\hline & Before treatment & After treatment & p-value \\
\cline { 2 - 4 } BMI & $26.4 \pm 5.6$ & $25.7 \pm 5.3$ & 0.475 \\
$\mathrm{BF} \%$ & $22.3 \pm 9.6$ & $20.4 \pm 11.6$ & 0.125 \\
\hline
\end{tabular}

\# paired t-test
TABLE 5: Cutometry measures of right and left buttocks before and after treatment

\begin{tabular}{llll}
\hline & $\begin{array}{c}\text { Before } \\
\text { treatment }\end{array}$ & $\begin{array}{c}\text { After } \\
\text { treatment }\end{array}$ & p-value \\
\cline { 2 - 4 } $\begin{array}{l}\text { R7 of the right } \\
\text { buttock }(\mathrm{mm} / \mathrm{sec})\end{array}$ & $0.773 \pm 0.104$ & $0.671 \pm 0.135$ & 0.027 \\
$\begin{array}{l}\text { R7 of the left } \\
\text { buttock }(\mathrm{mm} / \mathrm{sec})\end{array}$ & $0.753 \pm 0.090$ & $0.606 \pm 0.116$ & 0.004 \\
\end{tabular}

\# paired t-test

No significant difference was observed in any of the measurements obtained by high-resolution US images $(p>0.05)$, which shows that the treatment did not lead to any change in dermis or in the dermalhypodermal interface (Table 6). Figure 6 displays preand post-treatment images obtained by high-resolution US showing an apparent improvement in dermal echogenicity and a certain degree of rectification in dermal-hypodermal interface. However, considering mean values for all the measurements obtained by US images, there was no significant difference after 14 MLD sessions.

\section{DISCUSSION}

Although there are many therapeutic modalities for cellulite control, there is no evidence that any treatment provides satisfactory and lasting clinical results. In general, clinical studies evaluating treatments for cellulite are not randomized nor controlled, and the evaluation of efficacy is subjective, based on patients' opinion and on the comparison of photographs, which are not always taken in a standardized manner. ${ }^{10}$

Considering the multifactorial etiopathogeny of cellulite and the scarcity of studies with good methodology, the results of this study allow to suggest that the management of this skin condition requires a combination of treatments. ${ }^{1011,13-17,21,22}$

Since the etiopathogeny of cellulite involves several factors, particularly those of anatomical nature, isolated techniques are not able to act on all the changes promoted by cellulite. ${ }^{1,3,10}$

The most recommended therapeutic modalities in recent literature include balanced diet associated with physical activity and the use of devices with combined technologies such as RF, US, and laser. ${ }^{5,13-16,23} \mathrm{RF}$ is one of the most mentioned methods, but a recent review concluded that its results are modest and found mostly in non-randomized and non-controlled studies that assessed efficacy by subjective methods, which makes it difficult to draw conclusions about its benefit. ${ }^{14}$ A single-center, randomized, non-controlled study analyzed 20 women treated twice a week during six weeks with the TriActive ${ }^{\circledR}$ (Syneron, USA)device on one thigh and with VelaSmooth ${ }^{\circledR}$ 
TABLE 6: Descriptive measures obtained from high-resolution ultrasound images before and after treatment

\begin{tabular}{|c|c|c|c|}
\hline & Before treatment & After treatment & p-value ${ }^{\#}$ \\
\hline Dermal-hypodermal line in the right buttock or hip (pixels) & $13.329 \pm 0.859$ & $13.252 \pm 0.634$ & 0.728 \\
\hline Dermal-hypodermal line in the left buttock or hip (pixels) & $13.244 \pm 0.736$ & $13.533 \pm 1.011$ & 0.403 \\
\hline Thickness of the dermis in the right buttock or hip (pixels) & $1.670 \pm 0.371$ & $1.639 \pm 0.383$ & 0.614 \\
\hline Thicknesses of the dermis in the left buttock or hip (pixels) & $1.683 \pm 0.274$ & $1.650 \pm 0.315$ & 0.658 \\
\hline Collagen density of echogenicity of the right buttock or hip (pixels) & $0.275 \pm 0.121$ & $0.278 \pm 0.125$ & 0.918 \\
\hline Collagen density of echogenicity of the left buttock or hip (pixels) & $0.306 \pm 0.153$ & $0.267 \pm 0.094$ & 0.295 \\
\hline Dermal-hypodermal line in the right thigha (pixels) & $12.939 \pm 0.464$ & $12.994 \pm 0.814$ & 0.745 \\
\hline Dermal-hypodermal line in the left thigh ${ }^{\mathrm{b}}$ (pixels) & $13.113 \pm 1.139$ & $12.676 \pm 0.289$ & 0.161 \\
\hline Thickness of the dermis in the right thigh ${ }^{\mathrm{b}}$ (pixels) & $1.243 \pm 0.318$ & $1.187 \pm 0.227$ & 0.424 \\
\hline Thickness of the dermis in the left thigh ${ }^{b}$ (pixels) & $1.150 \pm 0.254$ & $1.212 \pm 0.321$ & 0.389 \\
\hline Collagen density of echogenicity of the right thigha (pixels) & $0.632 \pm 0.127$ & $0.667 \pm 0.127$ & 0.194 \\
\hline Collagen density of echogenicity of the left thigh ${ }^{\mathrm{b}}$ (pixels) & $0.675 \pm 0.135$ & $0.688 \pm 0.151$ & 0.613 \\
\hline
\end{tabular}
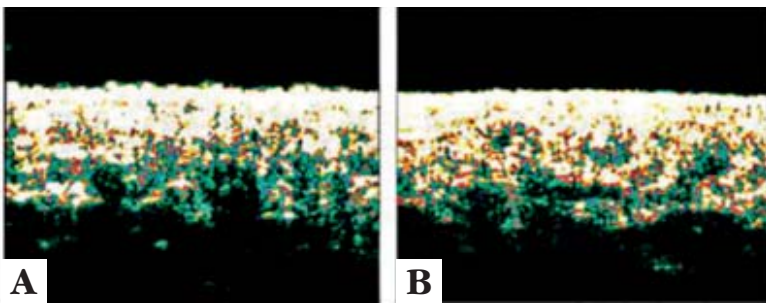

FIGURE 6: High-resolution ultrasound images from the right buttock of a patient before (A) and after (B) treatment showing improvement in hypodermal invagination towards dermis after 14 sessions of manual lymphatic drainage

(Cynosure, USA) on the other. The treatment with the TriActive system, which combines massage and $810 \mathrm{~nm}$ diode laser, led to a clinical improvement comparable to that provided by the VelaSmooth system, which combines infrared light, RF, and mechanical massage. Patients were assessed using pre- and posttreatment photographs and biometric measurements. Although both methods provided some improvement, results were not significant. ${ }^{16}$

Most studies found in the literature reviewed evaluate the efficacy of combined techniques. One of these studies, conducted with 21 women aged between 24 and 39 years, associated MLD with cavitational US, multipolar radiofrequency, endermologie, and LED. After eight treatment sessions, there was, on average, a reduction of $1.62 \mathrm{~kg}$ in weight and of 2.85 $\mathrm{cm}$ in abdominal circumference. However, most efficacy parameters were assessed subjectively. ${ }^{24}$

Although the majority of studies emphasize that only a combination of treatments may control cellulite, since its complete resolution does not seem possible, there is a need of studies with isolated modalities to evaluate the actual contribution of each moda- lity when combined with other modalities. Since MLD is a very popular, low-cost method that received satisfactory reports from women who used it, this study was proposed to evaluate the use of this technique in a protocolized manner.

Patients' adherence is crucial in the treatment of cellulite, which is usually long and not always provides results compatible with patient's expectations. Other factors, such as inadequate diet, lack of weight control, smoking, type of clothing, use of hormonal contraceptives, excessive exposure to the sun, etc., may negatively influence treatment outcomes. ${ }^{3,25}$ We believe that this study showed low adherence, because 5/20 women, or $25 \%$, did not complete the treatment. Patients who dropped out from the study earlier differed from those who completed it only in terms of diet control. We believe that this finding may be explained by the fact that dropout patients did not rely on the benefits of the treatment, which is well known and requires several sessions at short time interval. The participants of the present research did not receive any guidance on diet control, because the aim of the study was to evaluate the efficacy of MLD when performed in isolation; if this guidance was provided, diet could be a confounding factor. It is known that controlled diet resulting in healthy weight loss improves cellulite appearance due to the reduction in adipose tissue. ${ }^{5}$ In the present study, we decided not to recommend any food restriction, with the purpose of assessing the effect of MLD alone, because no study was found in the reviewed literature analyzing this widely used technique in isolation. Further studies should be designed to assess treatment combinations. Since the mass media has been announcing the "miraculous" effects of high cost devices, which many women cannot 
afford, therapeutic approaches with simpler techniques such as MLD have become less attractive.

Another important aspect that have been reported in the current scientific literature with increasing frequency is the investigation of the impact of dermatological diseases on patients' quality of life, which may be related not only to disease severity but also to discomfort, stigmatization, and social interference. ${ }^{25,26} \mathrm{~A}$ recent double-blind, randomized, controlled study, conducted at the same institution as this study, investigated the efficacy of the use of compression stockings reflecting long-wave infrared radiation in the control of cellulite. A positive impact was observed on women's quality of life, although there was no significant improvement in the appearance of cellulite. ${ }^{27}$

The present study found an improvement in the quality of life of women with cellulite, resulting from the significant reduction in mean DLQI scores $(\mathrm{p}$ $=0.018$, Wilcoxon) when comparing pre- and posttreatment scores, although all the other efficacy parameters evaluated showed discrete or null results.

Studies assessing the isolated role of MLD on cellulite control are scarce in the literature reviewed. In general, massage is associated with other resources, whether topical products or laser, RF and focused US devices. ${ }^{13,15,16}$ A previous study evaluated the effects of MLD on the lower limbs in only three patients who underwent 20 60-minute MLD sessions three times a week, using magnetic resonance imaging (MRI). MRI scans showed that this technique promoted the removal of excessive interstitial fluid and improved the general appearance of the skin. ${ }^{9}$

The effects of mechanical massage, MLD, and manipulation techniques were investigated in 60 women with cellulite divided into three groups of 20 . Women in group 1 underwent 15 sessions of mechanical massage; those in group 2 underwent 20 sessions of manipulation techniques; and those in group 3 underwent 20 MLD sessions. In addition to massage, the participants wore compression stockings during the intervals between sessions. The authors found that mechanical massage showed better results for suprailiac measures, while MLD promoted better results for thigh circumference. The analysis of the results was limited by the variable number of sessions and by the use of compression stockings. ${ }^{28}$

Another study observed a reduction of $1.62 \mathrm{~cm}$ in thigh diameter among 50 women after they applied a lotion containing garlic extract at a concentration of $0.0015 \%{ }^{29}$

The present study observed that only $33 \%$ of patients showed improvement in the grade of cellulite and a significant reduction in waist circumference, which was estimated at $0.3 \pm 0.8 \mathrm{~cm}$.

Surprisingly, none of the reviewed studies assessed bioelectrical impedance values, such as BMI and $\mathrm{BF} \%$. In the present study, it was found that both variables did not show significant reduction $(p>0.05)$ in mean values after treatment, confirming that MLD did not change either weight or body composition, which could favor the improvement of cellulite, as balanced diet and regular physical activity do.

Human skin has elastic and plastic features, due to dermal constituents and their organizational structure. Given its viscoelastic behavior, skin tends not to return immediately to its initial status when undergoing a temporary deformation in its structure caused by external forces. Life style (excessive exposure to sun, smoking, consumption of alcohol or illicit drugs, bad eating habits, and poor quality of sleep), as well as the use of cosmetic products and medications that could interfere with cell renovation and loss of transepidermal water, may also change skin mechanical properties. ${ }^{6}$ In this study, skin elastic and viscoelastic properties were measured before and after treatment using a suction device (cutometer). The only significant result $(\mathrm{p}<0.05)$ was the reduction in mean R7 measures for the buttocks, which indicated worsening of elasticity. We believe that MLD was not responsible for this finding but rather changes in life style or excessive exposure to sun during treatment, despite instructions provided to patients.

High-resolution US did not reveal any significant difference ( $p>0.05)$ in any of the measurements obtained, which indicates that the treatment did not promote any change in dermis or in dermal-hypodermal interface.

Because of the characteristics inherent to the therapeutic modality selected for this study, the limitations that could have influenced results are the following: sample size, low adherence, lack of control and randomization, number and duration of MLD sessions. Further studies involving a higher number of subjects, longer periods of treatment, and some sort of control may find other significant results. However, it is not possible to expect considerable changes in the clinical appearance of cellulite with the use of MLD alone, given its complex and incompletely understood nature. The contribution of this study is showing that this massage technique is safe but not effective as an isolated approach for cellulite management.

\section{CONCLUSION}

- MLD was ineffective when performed in isolation, although it promoted a significant reduction in hip circumference.

- MLD is a safe massage technique that does not cause discomfort.

- No correlation could be established between the measurements obtained using high-resolution US and clinical aspects.

- MLD led to a positive impact on quality of life. $\square$ 


\section{REFERENCES}

1. Nürnberger F, Müller G. So-called cellulite: an invented disease. J Dermatol Surg Oncol. 1978;4:221-9.

2. Quatresooz P, Xhauflaire-Uhoda E, Piérard-Franchimont C, Piérard GE. Cellulite histopathology and related mechanobiology. Int J Cosmet Sci. 2006;28:207-10.

3. Khan MH, Victor F, Rao B, Sadick NS. Treatment of cellulite. Part I Pathophysiology. J Am Acad Dermatol. 2010;62:361-70.

4. Emanuele E, Minoretti P, Altabas K, Gaeta E, Altabas V. Adiponectin expression in subcutaneous adipose tissue is reduced in women with cellulite. Int J Dermatol. 2011;50:412-6.

5. Smalls LK, Hicks M, Passeretti D, Gersin K, Kitzmiller WJ, Bakhsh A, et al. R. Effect of Weight Loss on Cellulite: Gynoid Lypodystrophy. Plast Reconstr Surg. 2006;118:510-6.

6. Bielfeldt S, Buttgereit P, Brandt M, Springmann G, Wilhelm KP. Non-invasive evaluation techniques to quantify the efficacy of cosmetic anti-cellulite products. Skin Res Technol. 2008;14:336-46

7. Hexsel DM, Dal'forno T, Hexsel CL. A validated photonumeric cellulite severity scale. J Eur Acad Dermatol Venereol. 2009;23:523-8.

8. Paolillo FR, Borghi-Silva A, Parizotto NA, Kurachi C, Bagnato VS. New treatment of cellulite with infrared-LED illumination applied during high-intensity treadmill training. J Cosmet Laser Ther. 2011;13:166-71.

9. Meyer PF, Martins NM, Martins FM, Moonteiro RA, Mendonça KMPP. Effects of lymphatic drainage on cellulits accessed by magnetic resonance. Braz Arch Biol Technol. 2008:5:1221-4.

10. Wanner M, Avram M. An evidence-based assessment of treatments for cellulite. J Drugs Dermatol. 2008;7:341-5.

11. Fink JS, Mermelstein H, Thomas A, Trow R. Use of intense pulsed light and a retinylbased cream as a potential treatment for cellulite: a pilot study. J Cosmet Dermatol. 2006:5:254-62.

12. Güleç AT. Treatment of cellulite with LPG endermologie. Int J Dermatol. 2009;48:265-70.

13. Manuskiatti W, Wachirakaphan C, Lektrakul N, Varothai S. Circumference reduction and cellulite treatment with a TriPollar radiofrequency device: a pilot study. J Eur Acad Dermatol Venereol. 2009;23:820-7.

14. Lolis MS1, Goldberg DJ. Radiofrequency in cosmetic dermatology: a review. Dermatol Surg. 2012;38:1765-76.

15. Fatemi A. High-intensity focused ultrasound effectively reduces adipose tissue. Semin Cutan Med Surg. 2009;28:257-62.

16. Nootheti PK1, Magpantay A, Yosowitz G, Calderon S, Goldman MP. A single center, randomized, comparative, prospective clinical study to determine the efficacy of the VelaSmooth system versus the Triactive system for the treatment of cellulite. Lasers Surg Med. 2006;38:908-12.

17. Adatto MA, Adatto-Neilson R, Novak P, Krotz A, Haller G. Body shaping with acoustic wave therapy $A W T \AA / E P A T \AA$ : randomized, controlled study on 14 subjects. J Cosmet Laser Ther. 2011;13:291-6.

18. Leduc $A$, Leduc 0 . Drenagem linfática teoria e prática. Traduzido por Marcos lkeda. São Paulo: Manole; 2000.

19. Godoy JMP, Godoy MFG. Drenagem linfática manual: novo conceito. J Vasc Bras. 2004; 3:77-80.

20. Landis JR, Koch GG. The measurement of observer agreement for categorical data. Biometrics. 1977;33:159-74.

21. de Godoy JM, Groggia MY, Ferro Laks L, Guerreiro de Godoy Mde F. Intensive treatment of cellulite based on physiopathological principles. Dermatol Res Pract. 2012;2012:834280.

22. Collis N, Elliot LA, Sharpe C, Sharpe DT. Cellulite treatment: a myth or reality: a prospective randomized, controlled trial of two therapies, endermologie and aminophylline cream. Plast Reconstr Surg. 1999;104:1110-4.

23. Costa A, Alves CRT, Pereira ESP, Cruz FAM, Fidelis MC, Frigerio RM, et al. Lipodistrofia ginoide e terapêutica clínica: análise crítica das publicações científicas disponíveis. Surg Cosmet Dermatol 2012;4:64-75.

24. Filippo AA, Salomão Júnior A. Tratamento de gordura localizada e lipodistrofia ginóide com terapia combinada: radiofrequência multipolar, LED vermelho, endermologia pneumática e ultrassom cavitacional. Surg Cosmet Dermatol 2012;4:241-6.

25. Finlay AY, Khan GK. Dermatology life quality index (DLQI) - a simple practical measure for routine clinical use. Clin Exp Dermatol. 1994;19:210-6.

26. Hexsel D, Siega C, Schilling-Souza J, Stapenhorst A, Rodrigues TC, Brum C. Avaliação dos aspectos psicológicos, psiquiátricos e comportamentais de pacientes com celulite: estudo-piloto. Surg Cosmet Dermatol 2012;4:131-6.
27. Bagatin E, Miot HA, Soares JL, Sanudo A, Afonso JP, de Barros Junior N, et al. Long-wave infrared radiation reflected by compression stockings in the treatment of cellulite: a clinical double-blind, randomized and controlled study. Int J Cosmet Sci. 2013;35:502-9.

28. Bayrakci Tunay V, Akbayrak T, Bakar Y, Kayihan H, Ergun N. Effects of mechanical massage, manual lymphatic drainage and connective tissue manipulation techniques on fat mass in women with cellulite. J Eur Acad Dermatol Venereol. 2010;24:138-42.

29. Treu C, Lupi O, Bottino D, Bouskela E. Parâmetros microcirculatórios e clínicos em pacientes com lipodistrofia ginoide tratadas topicamente com alho (15 ppM). Surg Cosmet Dermatol. 2009;1:64-9.
MAILING ADDRESS:
Bianca Schonvvetter
Rua Estado de Israel,192
Vila Clementino
04022-000 - São Paulo - SP
Brazil
E-mail: biavvetter@hotmail.com

How to cite this article: Schonvvetter B, Soares JLM, Bagatin E. Longitudinal evaluation of manual lymphatic drainage for the treatment of gynoid lipodystrophy. An Bras Dermatol. 2014;89(5):712-18. 